\title{
O CENÁRIO DA TERAPIA COMUNITÁRIA INTEGRATIVA NO BRASIL: HISTÓRIA, PANORAMA E PERSPECTIVAS
}

\author{
EL ESCENARIO DE LA TERAPIA COMUNITARIA INTEGRATIVA EN BRASIL: \\ HISTORIA, PANORAMA GENERAL Y PERSPECTIVAS
}

\section{THE SCENARIO OF INTEGRATIVE COMMUNITY THERAPY IN BRAZIL: HISTORY, OVERVIEW AND PERSPECTIVES}

\author{
Milene Zanoni da SILVA ${ }^{1}$ \\ Adalberto de Paula BARRETO ${ }^{2}$ \\ Josefa Emília Lopes RUIZ ${ }^{3}$ \\ Silvana Philippi CAMBOIM ${ }^{4}$ \\ Rolando LAZARTE ${ }^{5}$ \\ Maria de Oliveira Ferreira FILHA ${ }^{6}$
}

RESUMO: Este manuscrito, em forma de ensaio, é uma contribuição para a sistematização de informações e reflexões acerca do cenário da terapia comunitária integrativa no Brasil, desde a sua origem nos anos 80 até os dias atuais, apresentando sua trajetória, conquistas, desafios e perspectivas no que tange o cenário atual sociopolítico e de saúde. O objetivo é contextualizar historicamente a TCI no Brasil, com foco no cenário da TCI, em sua epistemologia, modus operandi e formação, sua relação com os determinantes sociais, perspectivas como Prática Integrativa e Complementar em Saúde inserida no sistema público de saúde brasileiro e repercussões de sua implementação no momento do COVID-19. Trata-se de um estudo de natureza teórico-conceitual, por meio da análise bibliográfica e da experiência empírica dos autores com o tema, sendo que Adalberto de Paula Barreto é o criador da TCI e as(os) autoras(es) são pesquisadora (es), terapeutas comunitárias(os), profissionais da saúde, docentes e membros da Associação Brasileira de Terapia Comunitária Integrativa (ABRATECOM).

${ }^{1}$ Universidade Federal do Paraná (UFPR), Curitiba - PR - Brasil. Professora do Departamento de Saúde Coletiva. Doutorado em Saúde Coletiva (UEL). Vice-presidente da Associação Brasileira de Terapia Comunitária (ABRATECOM). Membro Titular do Pólo Formador de Terapia Comunitária Integrativa - Shanti Instituto. ORCID: https://orcid.org/0000-0002-1177-9668. E-mail: milenezanoni@gmail.com

${ }^{2}$ Universidade Federal do Ceará (UFC), Fortaleza - CE - Brasil. Professor Emérito (UFC) e Professor Convidado da Haute École de Travail Social et de la Santé (EESP/Suiça). Doutorado em Psiquiatria (URD/França). Presidente da Associação Brasileira de Psiquiatria Social (Apsbra) e Criador da metodologia da Terapia Comunitária Integrativa. ORCID: https://orcid.org/0000-0003-3631-7643. E-mail: abarret.tci@gmail.com

${ }^{3}$ Universidade Estadual Paulista (UNESP), Araraquara - SP - Brasil. Psicóloga da Unidade Auxiliar do Centro de Pesquisas da Infância e da Adolescência (CENPE). Graduada no curso de Psicologia (USP). Presidente da Associação Brasileira de Terapia Comunitária Integrativa (ABRATECOM). ORCID: https://orcid.org/0000-00028636-5371. E-mail: josefa.ruiz@unesp.br

${ }^{4}$ Universidade Federal do Paraná (UFPR), Curitiba - PR - Brasil. Professora Adjunta. Doutora em Ciências Geodésicas (UFPR). Chair da Comissão de Tecnologias OpenSource da Associação Cartográfica Internacional. ORCID: https://orcid.org/0000-0003-3557-5341. E-mail: silvanacamboim@gmail.com

${ }^{5}$ Universidade Federal da Paraíba (UFPB), João Pessoa - PB - Brasil. Professor Aposentado e Terapeuta Comunitário. Doutorado em Sociologia (USP). Membro do Movimento Integrado de Saúde Mental Comunitária da Paraíba (MISC-PB). ORCID: https://orcid.org/0000-0003-0830-8432. E-mail: elzarat@gmail.com

${ }^{6}$ Universidade Federal da Paraíba (UFPB), João Pessoa - PB - Brasil. Docente no Programa de Pós Graduação em Enfermagem e Terapeuta Comunitária. Doutora em Enfermagem (UFC). ORCID: https://orcid.org/0000-00022400-6760. E-mail: marfilha@yahoo.com.br 
PALAVRAS-CHAVES: Terapias complementares. Saúde mental. Terapia comunitária integrativa. Sistema Único De Saúde. Apoio social.

RESUMEN: Este manuscrito, en forma de ensayo, es un aporte a la sistematización de información y reflexiones sobre el escenario de la terapia comunitaria integradora en Brasil, desde sus origenes en la década de 1980 hasta la actualidad, presentando su trayectoria, logros, desafios y perspectivas en el que concierne al actual escenario sociopolítico y sanitario. El objetivo es contextualizar históricamente las TIC en Brasil, enfocándose en el escenario de las TIC, en su epistemología, modus operandi y formación, su relación con los determinantes sociales, perspectivas como la Práctica de Salud Integrativa y Complementaria insertada en el sistema público brasileño y sus repercusiones. implementación en el momento de COVID-19. Se trata de un estudio de carácter teórico-conceptual, a través del análisis bibliográfico y la experiencia empírica de los autores con el tema, siendo Adalberto de Paula Barreto el creador de TCI y las (los) autoras (es) son investigadores, terapeutas comunitarios, profesionales de la salud, docentes y miembros de la Asociación Brasileña de Terapia Comunitaria Integrativa (ABRATECOM).

PALABRAS CLAVE: Terapias complementarias. Salud mental. Terapia comunitaria integradora. Sistema Único De Saúde. Apoyo social.

ABSTRACT: This manuscript, in essay form, is a contribution to the systematization of information and reflections on the scenario of integrative community therapy in Brazil, from its origin in the 1980s to the present day, presenting its trajectory, achievements, challenges and perspectives regarding the current socio-political and health scenario. The objective is to historically contextualize the ICT in Brazil, focusing on the ICT scenario, its epistemology, modus operandi and formation, its relationship with social determinants, perspectives such as Integrative and Complementary Health Practice inserted in the Brazilian public health system and repercussions of its implementation at the time of COVID-19. It is a theoretical-conceptual study, through bibliographic analysis and the authors' empirical experience with the topic. Adalberto de Paula Barreto is the creator of ICT and the authors are researchers, community therapists, health professionals, lecturers and members of the Brazilian Association of Integrative Community Therapy (ABRATECOM).

KEYWORDS: Complementary therapies. Mental health. Integrative Community Therapy. Sistema Único De Saúde. Social support.

\section{Introdução}

A Terapia Comunitária Integrativa (TCI) é uma prática terapêutica que fortalece e/ou cria vínculos e redes de solidariedade, resgata a autoestima e empodera as pessoas. Ela foi gerada dentro de um movimento social iniciado em 1985, por posse de terras em Fortaleza, no Estado do Ceará, Brasil. O criador da TCI, Adalberto de Paula Barreto, é doutor em psiquiatria, teologia e antropologia, e durante mais de 30 anos, atuou como professor da Faculdade de Medicina da Universidade Federal do Ceará (UFC). Ele atribui parte dessa criação ao seu irmão, 
Airton Barreto, advogado que exercia sua profissão no Centro de Direitos Humanos da Comunidade do Pirambú, naquela época, considerada a maior favela do Estado.

Pode-se afirmar que a TCI nasce num cenário de precária presença de políticas públicas, em um contexto de alta vulnerabilidade social marcado por grande restrição dos direitos humanos, tais como, saúde, segurança pública, acesso ao emprego e renda, bens e serviços, com elevado estigma social. Apesar dos maiores problemas vivenciados por aquela população estarem relacionados às desigualdades sociais, baixa autoestima, insegurança e abandono, a estratégia de intervenção para "solução" de tais dificuldades na comunidade era a medicalização.

Neste contexto, fazendo uma breve incursão na história, relembramos que a década de 1980, foi marcada pelas grandes lutas sociais dos trabalhadores, em busca da conquista de seus direitos sociais. Destacamos aqui o Movimento da luta Antimanicomial, que emergiu em 1987, como movimento contra hegemônico a psiquiatria clássica, pautada no modelo biomédico de medicalização da loucura e de exclusão dos “doentes mentais” (AMARANTE, 2007).

Com o restabelecimento da democracia, após um período de 21 anos de ditadura, os brasileiros voltaram a sonhar com a cidadania. Em 1985 ocorre a eleição direta para presidente da república e em 1988, com grande participação da sociedade civil organizada é elaborada e promulgada uma nova constituição para o país. O Brasil começava a sair da ditadura implantada em 1964. O movimento das diretas já, os comitês pela anistia, a mobilização de estudantes e professores, operários, artistas e jornalistas, abriam espaço para ações de natureza emancipatória. O Partido dos Trabalhadores, a imprensa alternativa, arejavam o cenário político nacional.

Para o campo da saúde significava uma mudança profunda em sua política. De acordo com o artigo 196 da Constituição, a saúde foi considerada direito de todos e dever do Estado. Nesse mesmo campo a saúde mental iniciava a luta pela reforma psiquiátrica, tendo como finalidade central a extinção dos manicômios.

Para o campo da Educação Pública Universitária, abria-se uma nova possibilidade de criar projetos de extensão, não somente de cunho assistencialista como era assinalado, mas com uma visão de sentido para a tomada de consciência da classe popular buscando os seus direitos negados pelo Estado e sobretudo, ampliar a sua visão de mundo, tendo como parâmetro a educação de Paulo Freire, cujo fundamento está em fazer com que a pessoa aprenda a se lê no mundo (KOCHANN, 2017).

Surge então a possibilidade de ampliar a frente libertadora para além da ação políticopartidária tradicional, enriquecendo a ação social com práticas de recuperação da identidade, 
da memória e da perspectiva histórica, quebrando o paradigma da dominação classista capitalista. Tal dominação tem como base de sustentação a alienação da pessoa, o desconhecimento de si, o estranhamento, o desconhecimento das próprias raízes, a negação do outro como correlato da negação de si próprio.

A TCI no contexto de ampliação da visão da prática da extensão e sua proposta vai exatamente na direção contrária a alienação e dissociação da pessoa. A institucionalização da prática ocorreu em 1988 através de um Projeto de Extensão do Departamento de Saúde Comunitária da UFC, e posteriormente ficou vinculada ao Movimento Integrado de Saúde Mental Comunitária (MISMEC). Na década de 90, o projeto de extensão na favela foi batizado como "Projeto Quatro Varas", sendo que até os dias atuais é desenvolvido um trabalho na área de promoção da saúde mental comunitária em Fortaleza. No quadro 1 apresenta uma linha do tempo com os marcos da TCI.

Em seu nascedouro, as primeiras intervenções de Adalberto ocorriam de maneira informal, na própria comunidade de Pirambú, onde ele e seus alunos do curso de medicina reuniam-se com pessoas da comunidade sob a sombra de um Cajueiro. Criava-se um espaço coletivo de fala, de escuta e construção de redes de apoio social, com foco nos cuidados em saúde mental.

A regularização desses encontros levou Adalberto a criar uma sistematização, um "passo a passo", para a realização dos mesmos. Posteriormente, esses encontros foram "batizados" de rodas de terapia comunitária, conceitualmente definida, com objetivos claros, eixos teóricos e com uma técnica simples, atualmente denominada de protocolo, que funciona como um guia para o terapeuta conduzir a roda (BARRETO, 2010).

A TCI não nasceu pronta, ela foi se construindo e construindo o criador em um movimento contínuo. A práxis barretiana é muito similar a práxis freiriana. Criador e criatura se constroem simultaneamente, compreendendo-se como ser/objeto em constante criação, sendo, portanto, inacabados. 
Quadro 1 - Linha do tempo de eventos importantes da TCI (2020)

\begin{tabular}{|l|l|}
\hline Ano & Eventos importantes \\
\hline 1987 & Criação da TCI em Pirambú \\
\hline Déc. De 90 & $\begin{array}{l}\text { Implantação do Projeto Quatro Varas (Movimento Integrado de Saúde Mental Comunitária } \\
\text { - MISMEC) }\end{array}$ \\
\hline Déc. De 90 & Primeiras formações em Terapia Comunitária Integrativa \\
\hline 2004 & Criação da Associação Brasileira em Terapia Comunitária Integrativa (ABRATECOM) \\
\hline 2006 & $\begin{array}{l}\text { Convênio da Secretaria Nacional de Políticas sobre drogas (SENAD) com a UFC e } \\
\text { MISMEC/Ceará para formação de terapeutas comunitários; }\end{array}$ \\
\hline \multirow{2}{*}{2008} & Diversos Convênios para Formação em TCI com Ministério da Saúde; \\
\cline { 2 - 2 } & Formação de terapeutas indígenas \\
\cline { 2 - 2 } & Projeto Calamidades \\
\cline { 2 - 2 } & $\begin{array}{l}\text { Inserção da TCI como proposta de ação na rede básica e na rede de cuidados em saúde } \\
\text { mental; }\end{array}$ \\
\cline { 2 - 2 } & Expansão para Europa \\
\hline 2017 & $\begin{array}{l}\text { Aprovação da TCI uma prática reconhecida na Política da Práticas Integrativas e } \\
\text { Complementares em Saúde (PICS) no Sistema Público de Saúde Brasileiro }\end{array}$ \\
\hline 2020 & Oferta de rodas de TCI online no momento de pandemia pelo COVID-19 \\
\hline
\end{tabular}

Fonte: elaborado pelos autores

A TCI fundamenta-se em cinco pilares: o pensamento sistêmico, a pragmática da comunicação humana, a antropologia cultural, a pedagogia de Paulo Freire e a resiliência. Assim, a TCI - além de ser um espaço aberto para a troca de experiências e sabedorias - cria vínculos e resgata a autonomia dos indivíduos, por facilitar a transformação de carências em competências, estimulando a resiliência comunitária, que os tornarão capazes de ressignificar momentos de dores e perdas (BARRETO, 2010).

O recurso que se utiliza na roda é a palavra, a fala, a comunicação verbal para dar voz e vez para as emoções. A palavra é um importante recurso terapêutico, uma vez que ao falar nos conectamos com a nossa essência, valorizando e dando espaço para a função psíquica especificamente humana, que é a nossa linguagem. A palavra dá visibilidade a um sofrimento escondido e permite a pessoa receber apoio do grupo.

A TCI apoia-se nas competências dos indivíduos e nos saberes produzidos pela experiência, uma vez que cada pessoa é um verdadeiro especialista na superação de suas dores e sofrimentos. Suas histórias de vida os têm tornado especialistas no enfrentamento de obstáculos na produção de um saber que é próprio.

Para além dos saberes da história de vida individual, o cerne da TCI reconhece o papel dos conhecimentos e sabedorias que culturalmente foram sendo construídos no núcleo familiar das pessoas, valorizando a herança, história, lutas e superações dos antepassados.

Partimos do princípio que cada pessoa, independente de seu nível socioeconômico e cultural, possui um saber que pode ser útil aos outros. E de onde vem este saber? Saber 
construído a partir da superação das dificuldades em sua própria trajetória. Pode-se amar porque foi amado, mas se pode amar porque foi rejeitado. A carência gera competência. Somos muito hábeis em dar aos outros aquilo que não recebemos. Mas também esses saberes, podem estar conectados a conhecimentos herdados, por vezes, inconscientemente, dos antepassados.

Quem é descendente dos indígenas tem o saber dos pajés, manipulando ervas medicinais pelo uso de chás, xaropes, cataplasmas. Os descendentes africanos têm o saber herdado dos pretos velhos, grandes conhecedores do valor medicinal das raízes e de rituais curativos afrobrasileiros. E isso sem falar no saber trazido pelos colonizadores Europeus e imigrantes asiáticos.

Existe grande potencial sociocultural à margem dos modelos hegemônicos institucionais. Com a TCI rompe-se com o modelo de educação vertical, autoritário e impositivo, onde os problemas dos indivíduos e das comunidades são providos de forma passiva e dependente por instituições e especialistas. Desta forma, questiona-se a dominação que faz da relação de "ajuda ao outro" um meio de oferecer "soluções" idealizadas, que geram dependência, respostas prontas que são por vezes coercitivas, punitivas e desconectadas da realidade da pessoa. Em vez de fazer algo para o outro, se faz algo com o outro, ou seja; fazemos juntos, escutando e buscando compreender seu contexto, seu mundo por meio de perguntas, semeando a dúvida nas certezas que o aprisionam (BARRETO, 2010).

Esse fundamento presente na TCI está respaldado no pensamento sistêmico, que concebe sistemas humanos formados por pessoas em interação intensa de modo tal que o comportamento de um membro afeta e é afetado pelo comportamento do outro. Neste contexto, toda situação problema deve ser vista dentro de um contexto mais amplo, compreendendo que fazem parte dos problemas todos aqueles envolvidos na situação e não apenas o membro problemático (BARRETO, 2010).

A pessoa, na abordagem sistêmica, é membro de uma rede relacional, dentro de uma realidade dinâmica, paradoxal e complexa, capaz de se autorregular, se autoproteger, se autotranscender e se autocurar. Dentro da visão dos princípios que norteiam a TCI, quando uma pessoa tem um problema ela também tem a solução dentro de si, tornando-se terapeuta de si mesma. Como dizia Carl Rogers, na abordagem centrada na pessoa "o ser humano tem a capacidade, latente ou manifesta, de compreender-se a si mesmo e resolver seus problemas de modo suficiente para alcançar a satisfação e eficácia necessárias ao funcionamento adequado" (ROGERS; KINGET, 1977, p. 39).

A TCI é uma possibilidade terapêutica potente para o indivíduo entrar em contato consigo mesmo saindo do seu estado de latência para manifestar o seu devir enquanto ser 
humano em busca do seu florescimento, com maiores níveis de felicidade, relações sociais positivas e sentido de vida. Assim, a TCI pode ser considerada como uma prática de saúde que estimula o potencial de reconexão do indivíduo com ele mesmo, num processo de autoconhecimento e transformação, que conduz a expressão e reconhecimento de seus sentimentos e emoções, aliados à sua crença, ao seu agir e pensar, dentro de seu sistema racional/cognitivo (SILVA et al., 2018).

Por vezes a pessoa não tem consciência da relação que existe entre seus sentimentos e desequilíbrios emocionais e biológicos. Ter um espaço terapêutico "protegido" de fala e de escuta, e também de reflexão através do diálogo com o outro, onde se legitima a dor física/emocional, não se julga, não se dá conselhos nem sermões, é um caminho para lidar com sentimentos que geram sofrimentos, muitas vezes responsáveis por somatizações ou complicações clínicas.

Por isso que muito comumente cita-se o adágio popular "quando a boca cala, os órgãos falam, mas quando a boca fala, os órgãos saram" para se referir ao pilar teórico da TCI - teoria da comunicação humana de Watzlawick, Beavin e Jackson (1973), pois neste referencial todo comportamento é comunicação e o corpo físico irá exteriorizar, na grande maioria das vezes, de forma inconsciente, por meio de desconfortos, sintomas e doenças, aquilo que vivemos no mais profundo de nós mesmos (BARRETO, 2014). O corpo tem uma sabedoria para apontar aquilo que está a favor ou contra a vida, e a epistemologia da TCI auxilia a perceber a doença não como um movimento unicausal de origem exclusiva biológica, mas como "linguagem simbólica da alma" e indicador que existe um desequilíbrio essencial que precisa ser visto e compreendido para que se alcancem níveis mais altos de consciência sobre si, seus corpos e seu processo saúde-doença-cuidado.

A possibilidade de fazer uma narrativa contextualizada sobre emoções que causam sofrimentos, e de ser indagado pelo terapeuta ou pelos participantes, sobre o sentido ou significado dessa angústia e seu impacto na saúde, além de ouvir o ponto de vista do outro, permite criar novas oportunidades da pessoa olhar para si e para o modo como seu corpo fala e reage mais conscientemente, repercutindo em seu processo saúde-doença.

Importante demarcar a especificidade da TCI, já que não é uma psicoterapia de grupo centrada sobre a doença ou biologização do sofrimento mental nem tampouco uma prática clínica - tal como o modelo biomédico faz - mas sim, um “cuidado solidário" que é realizado comunitariamente, com pessoas de qualquer nacionalidade, nível socioeconômico, idade, religião, orientação sexual, identidade de gênero, contexto. A TCI carrega em si uma abordagem integrativa de inclusão social, pois ela busca a diversidade das culturas, dos saberes 
e das competências, para enriquecer a dinamicidade das relações afetivas e trazer melhoria da autoestima, do empoderamento pessoal e coletivo (BARRETO, 2010).

\section{A técnica da Terapia Comunitária Integrativa}

A roda de TCI cria um contexto acolhedor em que o indivíduo redescobre seus valores e potenciais, assumindo o protagonismo da sua própria história, além de despertar-lhe o sentimento de pertencimento, valorizando suas raízes culturais.

As rodas de Terapia Comunitária Integrativa, que historicamente sempre foram presenciais - com o advento da pandemia do novo coronavírus -, também se tornaram virtuais, sem perder suas características de grupalidade e benefícios para a saúde emocional e comunitária.

Vale dizer que a presença humana se manifesta e se dá de várias maneiras. Uma pessoa participar de uma roda virtual de TCI pode ser um ato presencial ou não, dependendo da sua atitude, intenção, atenção, em outras palavras: a pessoa escolhe se ela está presente ou não. O mesmo ocorre nos encontros físicos, a pessoa pode estar presente em corpo, mas a mente não!

As rodas de TCIs só podem ser realizadas por terapeutas comunitários em formação ou capacitados por Polos de Formação reconhecidos pela ABRATECOM - Associação Brasileira de Terapia Comunitária, funcionam com um terapeuta e um coterapeuta a fim de garantir a condução adequada e exitosa da metodologia

O passo a passo da TCI consiste nas seguintes etapas: acolhimento, escolha da inquietação, contextualização, partilha da experiência e finalização (BARRETO, 2010). As etapas são processuais e progressivas, tornando cada roda um encontro com começo, meio e fim (REIS, 2017).

Cada etapa contempla um fazer com características e objetivos específicos e são as mesmas considerando a modalidade presencial ou virtual. O detalhamento de cada etapa está no quadro 2.

1. Acolhimento: é a alma da terapia comunitária, trabalha-se o processo de inclusão e pertencimento, é o momento de dar boas-vindas e dar espaço para a alegria de estarmos em grupo. O resultado positivo de uma Roda de TCI deve-se ao cuidado com essa etapa: socializase as regras (quadro 3), incluímos músicas, oferecendo um momento agradável, apresentamos a equipe de terapeutas e apresentamos ao grupo, o que é a TCI, de forma simples e direta, atribuindo a um espaço de partilha das nossas inquietações e conquistas. Nesta etapa são celebradas as conquistas de cada um, proposto uma dinâmica corporal para "quebrar o gelo" e 
permitir inteireza de cada participante na partilha, evitando permanecermos numa fala "intelectual" divorciada de nossas emoções.

2. Escolha da inquietação: A próxima etapa é a escolha da inquietação onde o terapeuta inicia perguntando sobre o motivo da presença de cada um e quais os sofrimentos que estão incomodando as (os) participantes na ocasião. O terapeuta procura estimular a importância de falar, de expressar sua dificuldade sempre fazendo apelo aos provérbios culturais. Costuma-se dizer: "Quando a boca cala os órgãos falam" e completamos: vamos falar com a boca para não falarmos com as doenças". Na roda o foco são as emoções e não os problemas. Feito isto, é solicitado ao grupo que escolha qual das histórias relatadas eles se identificam, pois como enfatiza Barreto "as pessoas se escolhem ao escolher o tema que as toca, pois só reconhecemos no outro aquilo que conhecemos em nós mesmos" (BARRETO, 2010, p. 69). Após esse momento, vem a votação em que será escolhida apenas uma inquietação para ser trabalhada naquela roda.

3. Contextualização: Logo a seguir, vem a etapa da contextualização quando as pessoas podem fazer perguntas para compreender melhor a inquietação que foi escolhida. Este momento é muito importante, já que, ao responder as perguntas feitas pelos outros participantes, a pessoa é estimulada à reflexão a respeito da sua própria história e todos do grupo que viveram esta mesma experiência conversam, também, consigo mesmas sobre suas angústias e ansiedades.

4. Partilha de Experiências: Após a contextualização, o protagonista fica em stand by e o grupo inicia a partilha de experiências. O terapeuta comunitário lança a pergunta, o mote (que é uma pergunta chave que vai permitir a reflexão do grupo durante a terapia): Quem já viveu algo parecido e o que fez para superar? Por exemplo: se o tema for insônia, vão emergir várias estratégias como uso de chás, exercícios, dança, canto, massagem. O protagonista que veio com um problema sai com várias possibilidades de manejo do seu sofrimento. Em outro caso, o senhor (no momento da inquietação) traz sua dor: "perdi a esperança de tirar meu filho das drogas”. Neste caso, não falamos da droga, mas da perda da esperança em geral lançando a pergunta para o grupo: "Quem um dia perdeu a esperança por qualquer que seja ela, e o que fez para recuperar”?. Vão emergir do grupo estratégias diversas. A partilha de experiências permite identificar os recursos locais desconhecidos e vai se formando uma rede de apoio social local. É pela partilha das experiências de vida que se alivia a dor da alma e se vai descobrindo que cada um tem um saber que pode ser útil ao outro?

5. Finalização: A última etapa é o encerramento onde se realizam rituais de agregação e conotação positiva, com o terapeuta agradecendo a presença e coragem de todos. Este 
momento pode ser criativo com a utilização de dinâmicas que as pessoas reconheçam e expressem afetividade, segurança, acolhimento, amizade, compreensão, entre outros.

6. Pós-roda: Após o término da roda de TCI, é realizada apreciação entre os terapeutas para avaliar os resultados e possibilidades de melhora.

\section{Quadro 2 - Síntese das etapas da Terapia Comunitária Integrativa (2020)}

\section{Acolhimento}

- Boas vindas: promover um espaço caloroso, de acolhimento e vínculo

- O que é a TCI? É um espaço de partilha das nossas inquietações e conquistas

- Destacar as regras da TCI

- Celebrações: aniversários, datas importantes, conquistas, superações

- Dinâmica de aquecimento

\section{Escolha da Inquietação}

- Por que falar na roda, do que falar e quem quer falar de suas inquietações;

- Restituição das histórias contadas pelas(os) participantes

- Síntese das inquietações

- Identificação: com qual inquietação(a) o participante se identifica e a justificativa;

- Votação da inquietação que tocou/sensibilizou as(os) participantes

- Agradecimento a todos que trouxeram suas dores;

\section{Contextualização}

- Início das perguntas e convite aos participantes para perguntarem para maiores esclarecimentos sobre a história mais votada;

- Preparação do mote

- Agradecimento ao protagonista da inquietação escolhida;

\section{Partilha das Experiências}

- Lançamento do mote: momento mais importante da roda, momento em que as pérolas surgem. É o coração da terapia comunitária integrativa.

- Partilha das experiências das pessoas que desejarem responder

- Agradecimento ao grupo

\section{Finalização}

- Ritual de agregação: roda de balanço

- Conotação de aprendizagem: o que eu aprendi e estou levando da roda

\section{Apreciação (momento pós-roda)}

- Apreciação da roda entre terapeutas comunitários

Fonte: Barreto (2010) e Mendonça (2012)

\section{Quadro 3 - Regras da Terapia Comunitária Integrativa}

\section{Regras da TCI}

1. Fazer silêncio quando alguém está falando: para respeitar a fala do outro e para exercitar a escuta ativa.

2. Falar apenas de si próprio e de como se sente em relação aos eventos que lhe acontecem, utilizando a primeira pessoa do singular: "Falar de si, usando o eu".

3. Jamais dar conselhos, sermões, fazer discursos e análise das histórias.

4. Regra da Cultura: Podem-se propor músicas, piadas, provérbios que tenham a ver com o tema.

Fonte: elaborado pelos autores 


\section{A TCI e as políticas públicas de saúde: ferramenta de cuidado em saúde mental}

A prática da TCI tem sido difundida exponencialmente tanto nacional quanto internacionalmente. Atualmente a TCI já se propagou em países da América, Europa e África. A TCI está presente em 27 países, entre eles: Chile, Paraguai, Argentina, Equador, México, Moçambique e Itália e França (MISMEC-CE, 2020). No Brasil, desde a sua criação, a TCI vem se expandindo em diferentes áreas, principalmente no setor público, tais como saúde, educação, justiça, direitos humanos, segurança pública e em calamidades públicas.

A consolidação nesses setores tem relação imbricada com parcerias estabelecidas, a partir de 2004, entre diversas instituições: Universidade Federal do Ceará (UFC), Associação Brasileira de Terapia Comunitária Integrativa (ABRATECOM), Fundação Cearense de Pesquisa e Cultura (FCPC), Secretaria Nacional Antidrogas (SENAD) e Ministério da Saúde (MS), com o objetivo de capacitar terapeutas comunitários em todo o país.

Até o ano de 2011 estimou-se a existência de mais de 30 mil Terapeutas Comunitários no Brasil (REIS, 2017), sendo que em apenas um convênio do MS, em 2008, foram capacitados mais de 1000 profissionais da área da saúde, em especial, Agentes Comunitários de Saúde (ACS), com o objetivo de fortalecimento da promoção da saúde mental na Atenção Primária à Saúde (APS).

No contexto do Sistema Único de Saúde, desde 2017, a partir da Portaria nº 849, de 27 de março de 2017, a TCI é uma das 29 Práticas Integrativas e Complementares em Saúde (PICS) e é classificada como intervenção psicossocial avançada de acordo com os Cadernos de Saúde Mental do Ministério da Saúde (BRASIL, 2013). A implantação da TCI no SUS e na Estratégia Saúde da Família é um movimento importante de mudança de uma política assistencialista para uma política de participação solidária e reorganização das redes de atenção à saúde, por meio da qual as políticas centram seus objetivos na promoção da saúde e desenvolvimento psicossocial das comunidades (ANDRADE et al., 2011; CEZÁRIO et al., 2015).

Atualmente, a TCI é uma das quatro PICS mais realizadas, em número de equipes atuantes da Atenção Primária à Saúde no Brasil, só ficando para trás de práticas milenares: práticas corporais da Medicina Tradicional Chinesa (16,6\%), plantas medicinais e fitoterapia $(14,9 \%)$ e acupuntura (12,7\%) (TESSER; SOUSA; NASCIMENTO, 2018). De acordo com Ministério da Saúde, as Práticas integrativas e Complementares em Saúde (PICS) são práticas e recursos buscam estimular os mecanismos naturais de prevenção de agravos e recuperação da saúde, com ênfase na escuta acolhedora, no desenvolvimento do vínculo terapêutico e na integração do ser humano com o meio ambiente e a sociedade (BRASIL, 2006). 
Apesar de TCI ser uma PICS de origem recente comparada a outras, como acupuntura e homeopatia, o fato de ser uma prática coletiva, genuinamente brasileira, potencialmente custoefetiva, que usufrui de recursos culturais e saberes populares e de vida para acolher o sofrimento humano e promover a saúde mental - justifica seu crescimento exponencial.

Em 2006, quando houve parceria entre o UFC/SENAD/MISMEC-CE, no projeto "Impacto da Terapia Comunitária como um recurso de prevenção do uso e abuso de álcool e outras drogas", 12 mil questionários foram preenchidos com o intuito de avaliar o impacto da TCI na vida e saúde dos protagonistas das rodas. Neste trabalho se identificou que os motivos pelos quais os participantes das rodas sofriam eram: estresse e emoções negativas $(26,7 \%)$ e; problemas familiares (19,7\%) (BARRETO, 2010).

Quanto ao encaminhamento para a Rede de Atenção Psicossocial (RAPS), apenas $11,5 \%$ foram indicados para os serviços de saúde, ou seja, $88,5 \%$ dos sofrimentos e dificuldades apresentados nas rodas de TCI encontraram solução na própria TCI (BARRETO, 2010).

Em outro estudo realizado em 2015 no município de Santa Terezinha de Itaipu, próximo a Foz do Iguaçu, a Terapia Comunitária Integrativa foi inserida como porta de entrada para os usuários na APS, o que possibilitou que a maioria dos indivíduos com baixo risco em saúde mental fossem acolhidos e acompanhados, utilizando racionalmente cada modalidade de atenção e cuidado em saúde (CORREA; SILVEIRA, 2015).

Assim, nesta pesquisa percebeu-se que com a implantação da TCI no município foi possível eliminar a demanda reprimida que existia nas Unidades Básicas de Saúde e acabar com a fila de espera, com aumento significativo da resolutividade na Atenção Básica em Saúde Mental (CORREA; SILVEIRA, 2015).

Essas informações trazidas sobre a TCI são relevantes para despertar e sensibilizar os gestores do Sistema Único de Saúde para recursos terapêuticos não-convencionais no cuidado em saúde mental, já que, historicamente, a assistência em saúde mental tem se alicerçado na patologização do sofrimento, com o uso desnecessário e irracional de antidepressivos, benzodiazepínicos e ansiolíticos, mesmo reconhecendo que amplamente que o sofrimento difuso ou queixas psicossomáticas não se enquadram nos critérios formais para diagnóstico de depressão e ansiedade segundo o Diagnostic and Statistical Manual of Mental Disorders V (DSM-V) e Classificação Internacional de Doenças 11 (CID-11).

O método da TCI se mostra com bom potencial de ser custo-efetiva como política pública, a partir de uma abordagem complementar não-medicalizadora - pois necessita de poucos recursos humanos e financeiros para sua realização e seu impacto, em especial nas dimensões psicoemocionais e sociais nas quais esse impacto é evidente -, além disso, traz a 
perspectiva de redução filas de espera por atendimentos individuais em saúde mental, otimizando as ações nas RAPS.

\section{Formação em TCI no contexto das PICS}

As capacitações em TCI iniciaram na década de 90 pelo Projeto Quatro Varas, ofertadas pelo Departamento de Saúde Comunitária da UFC. O projeto 4 varas implantou diversas ações terapêuticas tal como cuidando dos cuidadores, a massoterapia, plantas medicinais, arteterapia, yoga entre outros. Na época, eram ofertados 2 cursos para as lideranças: Curso de Terapia Comunitária Integrativa e de Abordagem Corporal Terapêutica (REIS, 2017). Em 33 anos de atuação, o Projeto 4 Varas já realizou mais de 2 milhões de atendimentos, com média de 3 mil atendimentos mensais (MISMEC-CE, 2020).

Das 29 PICS reconhecidas no sistema público de saúde brasileiro, a maioria delas se classifica como curso de oferta livre, incluindo a TCI bem como reflexologia, shantala, reiki e meditação. De acordo com o artigo 42, da Lei de Diretrizes e Bases da Educação Nacional, cursos livres são cursos cuja formação é aberta à comunidade, que não possuem carga horária preestabelecida e suas matrículas não estão condicionadas ao nível de escolaridade (BRASIL, 2005). Estes aspectos, quando se referem à formação em PICS, têm refletido em ofertas de cursos com baixa carga horária, à distância, de caráter apenas informativo, refletindo em baixa qualidade na formação técnica e humanística (NASCIMENTO et al., 2018).

Diferentemente de parcela relevante dos cursos livres ofertados na área de PICS no Brasil, a formação em Terapia Comunitária Integrativa é presencial, com, no mínimo, 240 horas, divididos em 100 horas de módulos teóricos com vivências para o resgate da autoestima pautadas em Branden (1994). Adicionalmente, tem-se 60 horas de estágio prático em que o terapeuta comunitário em formação necessita realizar 30 rodas de TCI em diferentes populações e contextos, a fim de se apropriar da metodologia e do "ser terapeuta", e 80 horas de intervisão, que objetiva estabelecer um diálogo entre a teoria e a prática, necessária à construção dessa nova forma de atuar nas comunidades.

Contudo, neste momento, em julho de 2020, com o advento da pandemia pelo novo coronavírus, a rede de formadores de terapia comunitária brasileira e latino-americana tem-se unido, para repensar a formação em TCI - considerando uma formação híbrida - em detrimentos das necessidades sanitárias e epidemiológicas de confinamento social, mas que não podem representar isolamento afetivo e emocional. 
Qualquer pessoa pode ser terapeuta comunitário, desde que tenha idade superior a 18 anos e que tenha desejo de fazer a formação. Não existe exigência acadêmica, pode ser leigo ou profissional. Contudo, é necessário ter afinidade com o trabalho em equipe, com a dimensão do social, seja legitimado pela comunidade e sinta-se corresponsável pela construção de uma cultura solidária.

As capacitações são ofertadas por Polos Formadores em TCI espalhados no Brasil, América Latina e Europa, que são vinculados à Associação Brasileira de Terapia Comunitária Integrativa (ABRATECOM) ou Associação Europeia de TCI (AETCI). Em julho de 2020 existiam 42 Polos Formadores, presentes nas 5 regiões do Brasil (15 Estados Brasileiros) e América Latina (Figura 1).

\section{TCI no contexto da pandemia pelo novo coronavírus}

De acordo com os dados dos registros dos Polos de Formação Brasileiros (SisRodas, 2020), Latino Americanos e Europeus, dos meses de março a julho a ABRATECOMAssociação Brasileira de Terapia Comunitária, em parceria com a Associação Brasileira de Psiquiatria Social, o Departamento de Saúde Mental Comunitária da Associação Mundial de Psiquiatria Social - apoiado pelo Observatório Nacional de Saberes Tradicionais, Complementares e Integrativos (ObservaPICS) e o Consórcio Acadêmico Brasileiro de Saúde Integrativa (CABSIN) - realizou 711 rodas de TCI online em 15 países, em 5 línguas diferentes (português, italiano, francês, espanhol e inglês), atingindo 11.500 pessoas aproximadamente. Recentemente, em publicação intitulada "Integrative Community Therapy in the Time of the New Coronavirus Pandemic in Brazil and Latin America”, evidenciou que, a partir das rodas online realizadas, as emoções vividas são as mesmas independente da cultura, mostrando que a dor e o sofrimento não têm fronteiras e nos une como humanidade. A TCI online tornou-se rede de apoio de resgate da esperança, implicando descoberta de potenciais desconhecidos, de transformações das adversidades da vida, de superação de si próprio (BARRETO et al., 2020). 
Figura 1 - Distribuição geográfica dos Polos de Formação em Terapia Comunitária no Brasil e América Latina (julho de 2020)

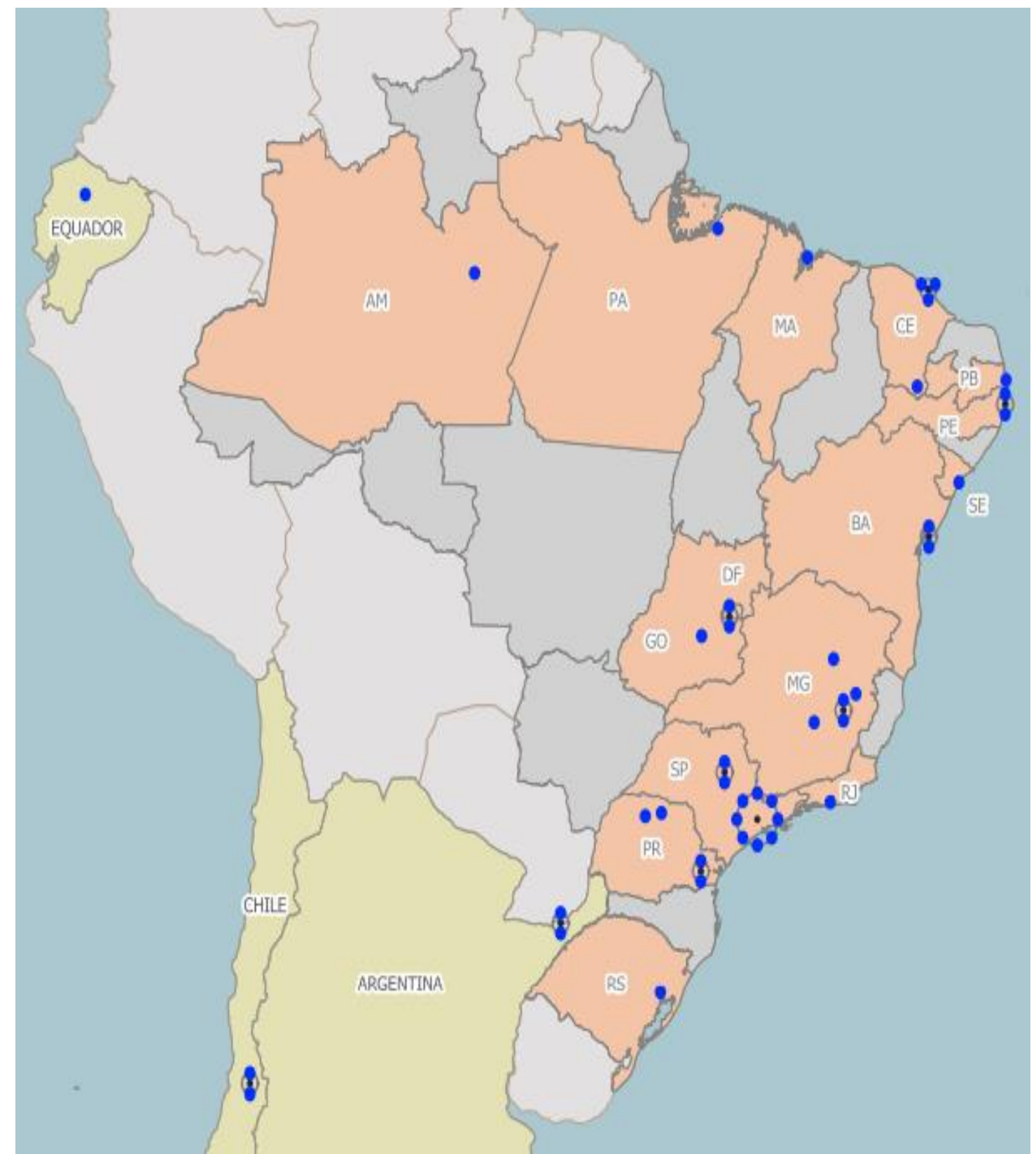

Fonte: elaborado pelos autores

Abaixo se encontra um quadro síntese de informações relevantes sobre a TCI, no que concerne conceitos, recursos, valores, método e formação (quadro 4). 
Quadro 4 - Quadro síntese sobre as principais informações sobre a Terapia Comunitária (julho de 2020).

\begin{tabular}{|c|c|}
\hline & Terapia Comunitária Integrativa \\
\hline Ano de criação & 1987 \\
\hline Criador & Adalberto de Paula Barreto \\
\hline País de Origem & Brasil \\
\hline Recursos Utilizados & $\begin{array}{l}\text { Recursos locais, culturais e comunitários expressos pela fala e linguagem } \\
\text { corporal que estimula a conexão da pessoa com suas emoções e história } \\
\text { de vida; }\end{array}$ \\
\hline $\begin{array}{l}\text { Classificação para o } \\
\text { Ministério da Saúde }\end{array}$ & $\begin{array}{l}\text { PICS inserida no SUS pela Portaria Ministerial GM no } 849 \text {, de } 27 \text { de } \\
\text { março de } 2017 \text { como intervenção psicossocial avançada. }\end{array}$ \\
\hline Abordagem & $\begin{array}{l}\text { Terapia interpessoal coletiva que ocorre com grandes grupos de pessoas } \\
\text { em um espaço protegido por regras que evitam manipulações ideológicas }\end{array}$ \\
\hline Valores & $\begin{array}{l}\text { Acolhimento; Simplicidade; Circularidade do cuidado; Valorização das } \\
\text { emoções; Ousadia e transgressão; Geração de Dúvidas nas convicções; } \\
\text { Horizontalidade das relações; Percepção do outro como recurso; } \\
\text { Aceitação da imprevisibilidade; Amor com bom humor }\end{array}$ \\
\hline Fundamentos teóricos & $\begin{array}{l}\text { Pedagogia da Autonomia de Paulo Freire } \\
\text { Antropologia Cultural } \\
\text { Pensamento Sistêmico } \\
\text { Teoria da Comunicação } \\
\text { Resiliência }\end{array}$ \\
\hline Etapas da Metodologia & $\begin{array}{l}\text { Acolhimento } \\
\text { Escolha da inquietação } \\
\text { Contextualização } \\
\text { Partilha de experiências } \\
\text { Finalização/Conotação positiva } \\
\text { Apreciação }\end{array}$ \\
\hline Formação em TCI & Curso livre de 240 horas \\
\hline
\end{tabular}

Fonte: elaborado pelos autores

\section{Considerações finais}

Neste artigo temos descrito alguns aspectos substantivos da TCI, que permitem visualizá-la como uma prática social libertadora que integra de maneira concreta e efetiva, recursos pessoais, comunitários e culturais, no sentido da construção de sujeitos sociais ativos e participativos, conscientes e criativos. Sadios. Rompe-se com o modelo da manipulação massificadora sobre a qual se estabelece o domínio de sociedades exploradoras que usam e descartam pessoas. Por se tratar de uma ação cidadã aberta e plural, respeitadora e potenciadora das diferenças, é um germe ativo e eficaz de sustentação de formas de vida humana significativas, plenas de sentido. Nada mais sadio do que a felicidade simples e plena.

Muito mais do que meramente uma ação de promoção da saúde e prevenção do adoecimento, a TCI é um espaço em que as pessoas recuperam a sua noção de si, o seu próprio valor, independentemente de sua relação com o mercado (utilidade, resultados, benefícios). Voltamos a perceber que somos uma realidade de valor incomensurável, não importa qual seja a nossa origem, posição social, orientação sexual ou crença religiosa. Na TCI não se prega 
ideologias nem dogmatismos, mas se praticam os valores supremos que dão sentido à vida; o não julgar, o acolhimento, re-conhecer-se na outra pessoa, criam uma amálgama de vínculos sociais positivos, conexões com afetos, pertencimento e enraizamento, favorecendo a ressignificação do sofrimento.

No meio a uma sociedade que se apresenta pautada em relações liquidas em um sistema político-econômico que se baseia na alienação e no esvaziamento da pessoa e de sua transformação em mero objeto, a TCI se consolida como uma ferramenta de humanização efetiva e eficaz que nos retira da apatia, do papel de vítimas, das sensações corporificadas de abandono e inutilidade. Cria-se vínculos em unidade, comunidade, que são um verdadeiro antídoto contra o desespero e a falta de sentido existencial que podem direcionar para comportamentos autodestrutivos. Na atual pandemia as rodas virtuais de TCI estão se configurando como uma estratégia para muitas pessoas saírem do estado de isolamento e solidão e se conectarem com a bela e ainda presente humanidade.

A TCI propõe um resgate do sensível em nossas relações e ações!

\section{REFERÊNCIAS}

AMARANTE, P. Saúde mental e atenção psicossocial. Rio de Janeiro: Editora Fiocruz, 2007.

ANDRADE, L. O. et al. The public health system and community therapy. Brasília: Ministério da Saúde, 2011.

BARRETO, A. P. Terapia comunitária: passo a passo. 4. ed. Fortaleza: LCR, 2010.

BARRETO, A. P. Quando a boca cala os órgãos fala: desvendando as mensagens dos sintomas. Fortaleza: LCR, 2014.

BARRETO, A. P. et al. Integrative community therapy in the time of the new coronavirus pandemic in Brazil and Latin America. World Soc Psychiatry, v. 2, p. 103-105, 2020.

BRANDEN, N. O poder da auto-estima. São Paulo: Sarava. 1994.

BRASIL. Ministério da Educação. Lei de Diretrizes e Bases da Educação Nacional. Brasília: Ministério da Educação, 2005. Disponível em: https://www2.senado.leg.br/bdsf/bitstream/handle/id/70320/65.pdf. Acesso em: 29 jul. 2020.

BRASIL. Ministério da Saúde. Secretaria de Atenção à Saúde. Departamento de Atenção Básica. Política Nacional de Práticas Integrativas e Complementares no SUS - PNPICSUS. Brasília: Ministério da Saúde, 92 p., 2006. 
BRASIL. Ministério da Saúde. Cadernos de atenção básica: saúde mental. Brasília: Ministério da Saúde, 2013.

BRASIL. Ministério da Saúde. Portaria n. 849, de 27 de março de 2017. Disponível em:http://bvsms.saude.gov.br/bvs/saudelegis/gm/2017/prt0849_28_03_2017.html. Acesso em: 29 jul. 2020.

CEZÁRIO, P. F. O. et al. Integrative Community Therapy and its Benefits for Primary Care: an Integrative Review. International Archives of Medicine, v. 8, n. 267, p. 1-9, 2015.

CORRÊA, R. S. Uma análise estratégica do processo de implementação da rede de atenção em saúde mental no município de Santa Terezinha de ITAIPU: as Rodas de Terapia Comunitária Integrativa como um instrumento de Educação Permanente em Saúde. 2015. Monografia (Trabalho de Conclusão do Curso de Especialização em Gestão do Trabalho e da Educação na Saúde) - Escola de Saúde Pública do Paraná/Escola Nacional de Saúde Pública Sergio Arouca/FIOCRUZ, Curitiba, 2015.

FERREIRA FILHA, M. O.; LAZARTE, R.; DIAS, M. D. Terapia Comunitária Integrativa: uma construção coletiva do conhecimento. João Pessoa: Editora UFPB, 2013.

FERREIRA FILHA, M. O.; LAZARTE, R.; DIAS, M. D. Terapia Comunitária Integrativa e a pesquisa/ação: estudos avaliativos. João Pessoa: Editora UFPB, 2019.

KOCHANN, A. A extensão universitária no Brasil: compreendendo sua historicidade. In: Semana de Integração, 6., 2017, Inhumas. Anais [...]. Inhumas, GO: UEG, p. 546-557, 2017.

MENDONÇA, M. E. Abordagem comunitária: terapia comunitária. In: MENDONÇA, M. E.; GUSSO, G.; LOPES, J. M. C. Tratado de medicina de família e comunidade: princípios, formação e prática. Porto Alegre: Artmed, 2012.

MISMEC-CE. Movimento Integrado Saúde Mental Comunitária. Comunidade que cuida. Portfólio Projeto 4 varas. Fortaleza, CE. 2020.

NASCIMENTO, M. C. et al. Formação em práticas integrativas e complementares em saúde: desafios para as universidades públicas. Trabalho, Educação e Saúde, v. 16, n. 2, p. 751$772,2018$.

REIS, M. L. A. Quando me encontrei voei: o significado da capacitação em Terapia Comunitária Integrativa. Porto Alegre: CAIFCOM Editora, 2017.

ROGERS, C. R.; KINGET, M. Psicoterapia e relações humanas. Teoria e prática da terapia não diretiva. 2. ed. Belo Horizonte: Interlivros, 1977.

SILVA, M. Z. et al. Práticas integrativas impactam positivamente na saúde psicoemocional de mulheres? Estudo de intervenção da terapia comunitária integrativa no sul do Brasil. Cad. $\mathbf{N}$ aturol. Terap. Complem, v. 7, n. 12, p. 33-42, 2018.

SISRODAS. Sistema de Registro de Rodas de Terapia Comunitária Integrativa: banco de dados. Organizado por Instituto Acreditar e Compartilhar Terapias Integrativas e 
Complementares Ltda. Disponível em: http://www.acreditarecompartilhar.com.br/rodas/login. Acesso em: 31 jul. 2020.

TESSER, C. D.; SOUSA, I. M. C. de; NASCIMENTO, M. C. do. Práticas integrativas e complementares na atenção primária à saúde brasileira. Revista Saúde em Debate, Rio de Janeiro, v. 42, n. 1, p. 174-188, set. 2018.

WATZLAWICK, P.; BEAVIN, J. H.; JACKSON, D. D. Pragmática da Comunicação humana. São Paulo: Cultrix, 1973.

\section{Como referenciar este artigo}

SILVA, M. Z. da; BARRETO, A. de P.; RUIZ, J. E. L.; CAMBOIM, S. P.; LAZARTE, R.; FILHA, M. de O. F. O cenário da Terapia Comunitária Integrativa no Brasil: história, panorama e perspectivas. Temas em Educ. e Saúde, Araraquara, v. 16, n. esp. 1, p. 341-359, set., 2020. e-ISSN 2526-3471. DOI: https://doi.org/10.26673/tes.v16iesp.1.14316

Submetido em: 20/05/2020

Revisões requeridas: $30 / 05 / 2020$

Aprovado em: 25/08/2020

Publicado em: 30/09/2020 